\title{
Hypothyroidism Increases Osmotic Water Permeability (Pf) in the Developing Renal Brush Border Membrane
}

\author{
JAAP MULDER, MAHA N. HADDAD, KIMBERLY VERNON, MICHEL BAUM, AND \\ RAYMOND QUIGLEY \\ Departments of Pediatrics [J.M., M.N.H., K.V., M.B., R.Q.] and Internal Medicine [M.B.], University of \\ Texas Southwestern Medical Center at Dallas, Dallas, Texas 75390-9063, U.S.A.
}

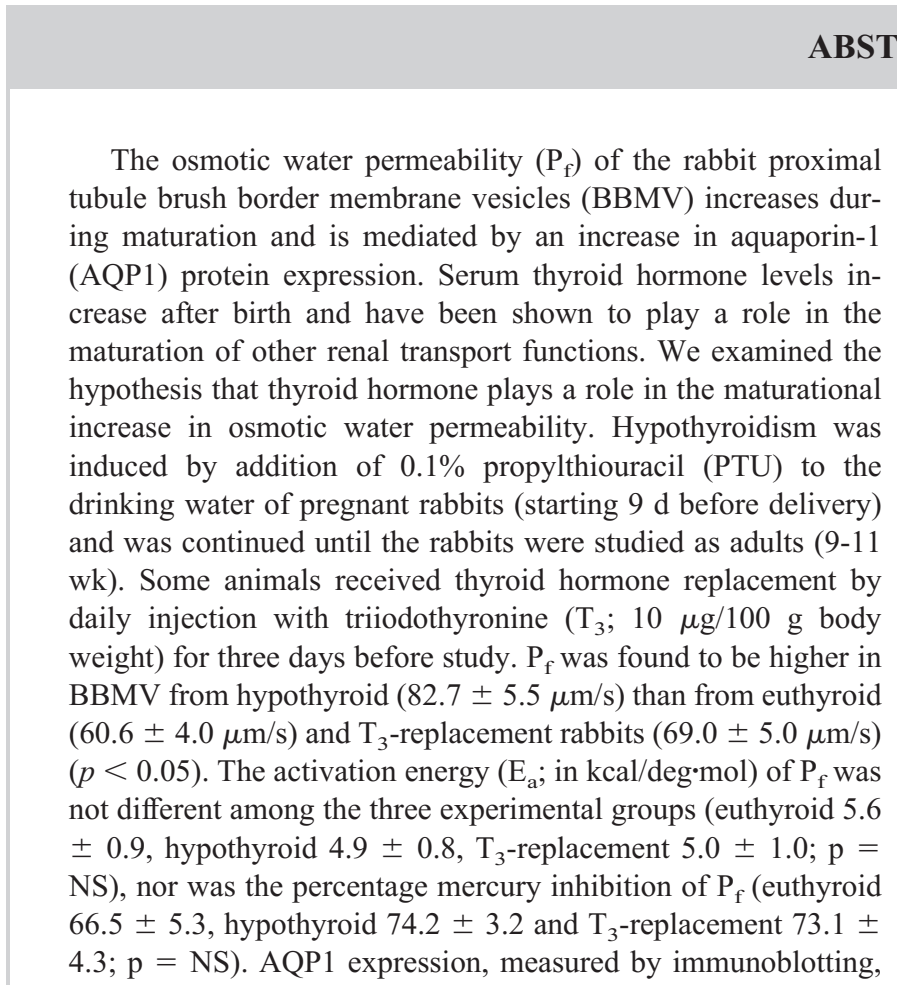

The proximal tubule reabsorbs approximately two-thirds of the glomerular ultrafiltrate (1). This occurs in a nearly isoosmotic manner due to the high water permeability of this segment. We have previously demonstrated that the osmotic water permeability of both apical (brush border) and basolateral membranes increased during postnatal development $(2,3)$. In both membranes, this was accompanied by an increase in

Received September 17, 2002; accepted December 23, 2002.

Correspondence: Raymond Quigley, M.D., Department of Pediatrics, U. T. Southwestern Medical Center, 5323 Harry Hines Boulevard., Dallas, Texas 75390-9063, U.S.A.; e-mail: raymond.quigley@utsouthwestern.edu

Jaap Mulder was supported by the Rijksuniversiteit Groningen, the Netherlands and the Dutch Kidney Foundation. This work was supported by National Institute of Diabetes and Digestive and Kidney Disease Grants DK-41612 (to M. Baum).

DOI: 10.1203/01.PDR.0000061567.32928.8B

was highest in BBMV from hypothyroid rabbits $(p<0.05)$. Membrane fluidity, measured as steady-state generalized polarization (GP) of Laurdan, which is inversely related to membrane fluidity, was significantly different between the three groups (GP: euthyroid $0.307 \pm 0.004$, hypothyroid $0.271 \pm 0.004$ and $\mathrm{T}_{3}-$ replacement $0.287 \pm 0.003$; for all $p<0.05$ ). These data demonstrate that the maturational increase in thyroid hormone levels is not responsible for the maturational increase in water transport. Surprisingly, congenital hypothyroidism in rabbits is associated with an increased $\mathrm{P}_{\mathrm{f}}$ when rabbits are studied as adults. The higher $\mathrm{P}_{\mathrm{f}}$ in hypothyroid adult rabbits is due to a higher expression of AQP1 protein as well as a greater membrane fluidity than in euthyroid rabbits. (Pediatr Res 53: 10011007, 2003)
AQP1, aquaporin 1

\section{Abbreviations}
BBMV, brush border membrane vesicles
PTU, propylthiouracil
GP, generalized polarization
$\mathbf{P}_{\mathbf{f}}$, osmotic water permeability
$\mathbf{E}_{\mathbf{a}}$, activation energy

aquaporin-1 (AQP1) expression; the predominant water channel in proximal tubular membranes (4).

The factors that are responsible for the maturational change in proximal tubule water transport and AQP 1 expression remain unknown. Thyroid hormone levels rise postnatally (5, 6) and have been shown to be a factor in developmental changes in proximal tubular function, including $\mathrm{NaCl}$ transport (7), $\mathrm{Na}^{+} / \mathrm{H}^{+}$-antiporter activity (5) and phosphate transport (6). The role of thyroid hormone with regard to maturation of water transport in the proximal tubule remains unknown.

The aim of the present study was to investigate the effect of thyroid hormone on the development of proximal tubule water transport. Our hypothesis was that the postnatal increase in thyroid hormone is necessary for the increase in proximal tubule AQP1 expression. We examined the effects of chemi- 
cally induced hypothyroidism on the osmotic water permeability $\left(\mathrm{P}_{\mathrm{f}}\right)$ of rabbit renal BBMV functionally and at the level of protein abundance. We also studied the effect of hypothyroidism on another important factor in water permeability of BBMV, namely membrane fluidity (8).

\section{METHODS}

Animals. Pregnant New Zealand White rabbits were housed at our institution for at least $9 \mathrm{~d}$ before delivery. The protocol for these studies was approved by the Institutional Animal Care and Research Advisory Committee. They were kept on a 12 $\mathrm{h}-12 \mathrm{~h}$ light-cycle, at an ambient temperature of $16-22^{\circ} \mathrm{C}$ and were fed standard laboratory chow. Pups were cared for by their mother until weaned and were studied at 9-11 wk of age. Hypothyroidism was induced in pups by treatment with propylthiouracil (PTU), which prevents the postnatal increase in serum thyroid hormone levels (thyroxine) (7). Treatment was initiated $9 \mathrm{~d}$ before birth by adding $0.1 \%$ PTU to the drinking water of pregnant does and was continued until study (adulthood, 9-11 wk). Thyroid replacement (" $T_{3}$-replacement") therapy was given with daily s.c. injections with 3,5,3'triiodothyronine $\left(\mathrm{T}_{3}, 10 \mu \mathrm{g} / 100 \mathrm{~g}\right.$ body weight) for $3 \mathrm{~d}$ including $2 \mathrm{~h}$ before sacrifice as previously described in our laboratory (7). Age matched control pups and their mothers had access to tap water.

Materials. Chemicals were purchased from Sigma Chemical Co.-Aldrich (St. Louis, MO, U.S.A.) and Fluka BioChemika (Buchs, Germany). 6-Dodecanoyl-2-dimethylaminonaphtalene (Laurdan) was obtained from Molecular Probes (Eugene, OR, U.S.A.). Anti-AQP1 antibody was purchased from Alomone Labs (Jerusalem, Israel), anti- $\beta$-actin from Sigma Chemical Co.-Aldrich and horseradish peroxidase-conjugated anti-rabbit MAb from Amersham (Arlington Heights, IL, U.S.A.). Solution osmolalities were measured by freezing point depression (Advanced Instruments, Norwood, MA, U.S.A.; osmometer model 3D3).

Serum thyroid hormones. Blood was collected at time of sacrifice and centrifuged at $1500 \mathrm{rpm}$ for $10 \mathrm{~min}$. Serum was frozen at $-80^{\circ} \mathrm{C}$. Serum concentrations of triiodothyronine $\left(\mathrm{T}_{3}\right)$ and thyroxine $\left(\mathrm{T}_{4}\right)$ were assessed with radioimmunoassays (Diagnostic Systems Laboratories, Webster, TX, U.S.A.).

Brush border membrane vesicle preparation. Brush border membrane vesicles were prepared as described previously in our laboratory $(9,2)$. Briefly, kidneys were removed promptly and immediately placed in ice-cold PBS $(137 \mathrm{mM} \mathrm{NaCl}, 2.7$ $\mathrm{mM} \mathrm{KCl}, 10.1 \mathrm{Na}_{2} \mathrm{HPO}_{4}, 1.7 \mathrm{mM} \mathrm{KH_{2 }} \mathrm{PO}_{4}, \mathrm{pH}$ 7.4). Kidneys from 3-5 neonates were pooled. The capsule was removed and the cortex was dissected. After mincing, the cortex was transferred into isolation buffer $(300 \mathrm{mM}$ D-mannitol, $16 \mathrm{mM}$ HEPES, 5 mM EGTA, adjusted to $\mathrm{pH} 7.5$ with Tris- $\mathrm{HCl}$; protease inhibitors aprotinin $(2 \mu \mathrm{g} / \mathrm{mL})$, leupeptin $(2 \mu \mathrm{g} / \mathrm{mL})$ and phenylmethylsulfonyl fluoride $(175 \mu \mathrm{g} / \mathrm{mL}))$. Tissue was homogenized by 15 strokes with a Potter homogenizer, after which cell precipitation was induced using $230 \mu \mathrm{L}$ of $1.0 \mathrm{M}$ $\mathrm{MgCl}_{2}$. The homogenate was shaken vigorously for $10 \mathrm{~s}$ every $5 \mathrm{~min}$ for $20 \mathrm{~min}$. Subsequently, the homogenate was centrifuged at $2500 \times g$ for $15 \mathrm{~min}$ at $4^{\circ} \mathrm{C}$. The supernatant was aspirated, added to $230 \mu \mathrm{L} 1.0 \mathrm{M} \mathrm{MgCl}_{2}$ and shaken vigorously for $10 \mathrm{~s}$ every $5 \mathrm{~min}$ for $20 \mathrm{~min}$, then centrifuged for 15 $\min$ at $2500 \times g$ at $4^{\circ} \mathrm{C}$. The supernatant was then centrifuged at $48,400 \times g$ for $30 \mathrm{~min}$ at $4^{\circ} \mathrm{C}$. The pellets were resuspended in $1.5 \mathrm{~mL}$ ice-cold resuspension buffer (5.0 mM HEPES, $\mathrm{pH}$ 7.4; osmolality adjusted to 80 mosmol with d-mannitol). The protein content was determined in the crude homogenate and BBMV using BCA protein assay (Pierce, Rockford, IL). Alkaline phosphatase activity was determined to assess enrichment, as previously described $(9,2)$. There was no difference in enrichment between control, hypothyroid and $\mathrm{T}_{3}$-replacement animals (fold increase, respectively $6.0 \pm 0.4,7.0 \pm 1.0$ and $6.1 \pm 0.8, \mathrm{p}=\mathrm{NS})$.

Stopped-flow kinetics. BBMV were brought to a concentration of $0.6 \mathrm{mg}$ protein $/ \mathrm{mL}$. BBMV $(100 \mu \mathrm{L})$ were rapidly mixed with 240 mosmol resuspension buffer $(100 \mu \mathrm{L})$ using a stopped-flow apparatus (SFM-3, Biologic, France). These solutions are routinely used in measuring water permeability and have previously been used in our laboratory $(2,3$, and 8$)$. The cuvet was illuminated using a $75 \mathrm{~W}$-xenon arc lamp and a monochrometer that was set at $400 \mathrm{~nm}$. Light scattering was measured using a photomultiplier tube (Biologic, France) oriented at a $90^{\circ}$ angle with regard to the illumination axis. Data were collected at $10 \mathrm{~ms}$ intervals for $2 \mathrm{~s}$ using Bio-kine software (Biologic, France). Five raw tracings were averaged and analyzed subsequently. $\mathrm{P}_{\mathrm{f}}$ was calculated as previously described (3). Briefly, the osmotic water permeability was calculated from the stop-flow light scattering data as described by Van Heeswijk et al. (10). The scattered light intensity was normalized to an initial value of 1 , then fit to a double exponential curve:

$$
I(t)=b-c_{1} e^{-k_{1} t}-c_{2} e^{-k_{2} t}
$$

where $I(t)$ is the light intensity at time $t, b$ is the asymptote, $c_{\mathrm{i}}$ are the coefficients and $k_{\mathrm{i}}$ are the rate constants. The mean rate constant was determined by the following equation:

$$
\bar{k}=\frac{c_{1} k_{1}+c_{2} k_{2}}{c_{1}+c_{2}} .
$$

$\mathrm{P}_{\mathrm{f}}$ was then calculated from the following equation:

$$
\bar{k}=\bar{V}_{w} \mathrm{P}_{\mathrm{f}}\left(A / V_{0}\right) C_{m},
$$

where $\bar{V}_{w}$ is the molar water volume, $A / V_{0}$ is the surface area to initial vesicle volume ratio and $C_{m}$ is the osmolality of the extravesicular solution. The initial surface area to volume ratio was calculated assuming that the vesicles were spheres. We had previously demonstrated that the diameters of the neonatal and adult BBMV is $200 \mathrm{~nm}$ that was used in the present calculations (2).

Temperature dependence and mercury-sensitivity. To examine the activation energy $\left(E_{a}\right)$ of $P_{f}$, experiments were conducted at $20,25,33$ and $40^{\circ} \mathrm{C}$. $\mathrm{E}_{\mathrm{a}}$ was calculated from the slope of the Arrhenius plot (ln $\mathrm{k}$ versus temperature ${ }^{-1}$ (11, 12)):

$$
\mathrm{Ea}=-[\text { slope } \times \mathrm{R}]
$$


where $R$ is the gas constant (1.987 kcal.deg-1.mol-1). The slope was determined using linear regression analysis. The temperature dependence of water transport gives valuable insight into the mechanism of water movement. Channel mediated water flow has a low activation energy while water movement through the lipid bilayer has a high activation energy $(8,12)$.

Inhibition of water transport across water channels was studied by incubating BBMV with $0.5 \mathrm{mM} \mathrm{HgCl}_{2}$ at room temperature $\left(\sim 23^{\circ} \mathrm{C}\right)$ for $10 \mathrm{~min}$ and measuring $\mathrm{P}_{\mathrm{f}}$ at $20^{\circ} \mathrm{C}$.

Immunoblotting for AQP1. Immunoblots were performed as described previously $(2,3)$. Briefly, BBMV samples $(40 \mu \mathrm{g}$ total protein) were brought to a $50 \mu \mathrm{L}$ volume using isolation buffer. After addition of $10 \mu \mathrm{L}$ loading buffer, samples were heated to $95^{\circ} \mathrm{C}$ for $5 \mathrm{~min}$, chilled on ice and loaded on a $10 \%$ SDS gel. Samples were transferred overnight onto PVDF membrane at $4^{\circ} \mathrm{C}$.

Anti-AQP1 was used at 1:1,000 and anti- $\beta$-actin at 1:5,000 dilutions. After preincubation with Blotto, membranes were incubated with the primary antibody at room temperature for two hours, washed four times over $40 \mathrm{~min}$, and incubated with the secondary antibody at room temperature for one hour. Detection was done using ECL kit (Amersham).

Membrane fluidity measurements. Membrane fluidity was assessed with the use of Laurdan, a fluorophore sensitive to the polarity of its environment (13). Penetration of water into the membrane causes a spectral shift and increased emission at 490 $\mathrm{nm}$. Generalized polarization (GP) is used to quantify this shift from the following relation:

$$
\mathrm{GP}_{\text {laurdan }}=\left[\mathrm{I}_{440}-\mathrm{I}_{490}\right] /\left[\mathrm{I}_{440}+\mathrm{I}_{490}\right]
$$

where $\mathrm{I}_{440}$ and $\mathrm{I}_{490}$ are the emission intensities at $440 \mathrm{~nm}$ and $490 \mathrm{~nm}$, respectively (13).

BBMV $(100 \mu \mathrm{g}$ protein) were incubated with $0.33 \mathrm{nmol}$ of Laurdan at $37^{\circ} \mathrm{C}$ for $>20$ min. Using a photon counting spectrofluorometer (PC1, ISS Inc., Urbana-Champaign, IL, U.S.A.), samples were excited at $340 \mathrm{~nm}$. Emission intensities were measured at $440 \mathrm{~nm}$ and $490 \mathrm{~nm}$. Experiments were conducted at $37^{\circ} \mathrm{C}$. Generalized polarization was subsequently calculated using ISSPC software (ISS Inc.).

Statistical analysis. Data were analyzed using SigmaStat statistical software (Jandel Corporation, San Rafael, CA, U.S.A.). Data are presented as means ( \pm SEM). For measures of osmotic water permeability, each preparation was measured at each temperature so that the data were analyzed using two-way repeated measures ANOVA. Where the preparation was used once, the data were analyzed using Student's $t$-tests and one-way ANOVA, according to the design of the experiment.

\section{RESULTS}

Serum thyroid levels. Serum levels of thyroid hormone are shown in Table 1. The suppression of thyroid function in PTU-treated animals was evident from a significantly lower serum concentration of $T_{4}$ in both the hypothyroid and $T_{3^{-}}$ replacement groups. In hypothyroid animals, the levels of the active compound $T_{3}$ were reduced by approximately one-third
Table 1. Serum thyroid hormone levels

\begin{tabular}{lll}
\hline \multicolumn{1}{c}{ Group $(N)$} & $\mathrm{T}_{3}(\mathrm{ng} / \mathrm{dL})$ & $\mathrm{T}_{4}(\mu \mathrm{g} / \mathrm{dL})$ \\
\hline Euthyroid $(10)$ & $178 \pm 18$ & $4.2 \pm 0.4$ \\
Hypothyroid $(9)$ & $120 \pm 12 \dagger$ & $1.5 \pm 0.1 \ddagger$ \\
$\mathrm{T}_{3}$-replacement $(10)$ & $>1000 \ddagger \#$ & $1.5 \pm 0.1 \ddagger$ \\
\hline$\dagger p<0.05$ vs. euthyroid. & & \\
$\$ p<0.001$ vs. euthyroid. & & \\
$\# p<0.001$ vs. hypothyroid. & &
\end{tabular}

compared with control, euthyroid animals. $\mathrm{T}_{3}$-replacement was confirmed to be effective by the high levels of $\mathrm{T}_{3}$ measured $2 \mathrm{~h}$ after the last dose of $\mathrm{T}_{3}$.

Osmotic water permeability. Representative tracings for the three experimental groups are shown in Fig. 1 . At $20^{\circ} \mathrm{C}$, vesicles from hypothyroid animals had a faster rate of change in BBMV volume, measured as a change in light scattering due to an imposed osmotic gradient, compared with controls. $\mathrm{T}_{3}$ replacement for three days resulted in rates that were comparable to controls. Calculation of $\mathrm{P}_{\mathrm{f}}$ showed similar results at all four temperatures studied (Fig. 2). The results showed that congenital hypothyroidism was associated with a significant increase in $\mathrm{P}_{\mathrm{f}},(p<0.05$ versus euthyroid). This effect was fully reversed by $\mathrm{T}_{3}$-replacement ( $p=\mathrm{NS}$ versus euthyroid and $p<0.05$ versus hypothyroid).

Activation energy. The activation energy of the osmotic water permeability of each experimental group was calculated from the slope of the Arrhenius plot (Fig. 3). The temperature dependence, and thus the $\mathrm{E}_{\mathrm{a}}$ of the BBMV $\mathrm{P}_{\mathrm{f}}$, was not different between the three groups.

Mercury inhibition. The addition of $0.5 \mathrm{mM} \mathrm{HgCl}_{2}$ to BBMV caused not only a change in rate-constant $(k)$, but a decrease in signal amplitude as well. To take this observation into account, the degree of inhibition of $\mathrm{P}_{\mathrm{f}}$ by $\mathrm{HgCl}_{2}$ was calculated from the initial slope of the averaged tracings. The percentage inhibition was not different among the three groups (euthyroid $66.5 \pm 5.3$, hypothyroid $74.2 \pm 3.2$ and $\mathrm{T}_{3}$ replacement $73.1 \pm 4.3 ; p=\mathrm{NS}$ ).

\section{Immunoblot}

The protein abundance of $\mathrm{AQP} 1$ and $\beta$-actin is shown in Fig. 4. Densitometry showed that hypothyroidism significantly increased the expression of AQP1 in the renal brush border membrane $(\mathrm{AQP} 1 / \beta$-actin ratio: hypothyroid $3.27 \pm 0.81$, control $0.66 \pm 0.33, \mathrm{~T}_{3}$-replacement $0.85 \pm 0.36 ; p<0.05$ ). There was no difference between the control group and the animals that received $\mathrm{T}_{3}$ replacement to correct their hypothyroidism.

\section{Membrane fluidity}

Membrane fluidity was measured to examine an aspect of water transport other than the expression of AQP1 that may contribute to the effects of hypothyroidism and $\mathrm{T}_{3}$-replacement on $\mathrm{P}_{\mathrm{f}}$ (Fig. 5). Generalized polarization of Laurdan was significantly lower in hypothyroid than in euthyroid BBMV $(p<$ 0.001). This effect of hypothyroidism was only partially reversed by $\mathrm{T}_{3}$-treatment. Since a lower generalized polarization corresponds to a higher membrane fluidity, this indicates that 


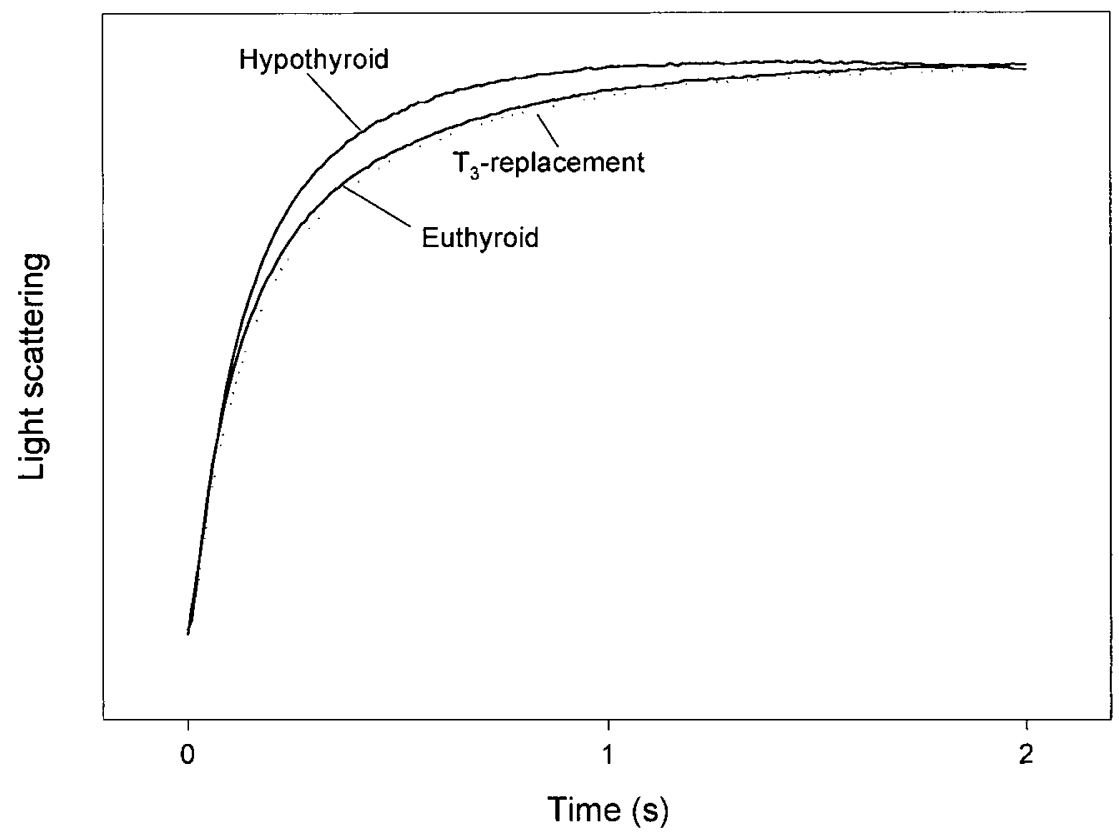

Figure 1. Typical tracings for measurement of $\mathrm{P}_{\mathrm{f}}$ in euthyroid, hypothyroid and $\mathrm{T}_{3}$-replacement (dotted line) $\mathrm{BBMV}$ at $20^{\circ} \mathrm{C}$. BBMV were prepared with 80 mosmol resuspension buffer and rapidly mixed with an equal volume of 240 mosmol resuspension buffer, creating an inward osmotic gradient of 80 mosmol. Vesicle shrinkage increased light scattering. Averaged tracings were normalized to initial fluorescence and fitted to a double-exponential curve.

hypothyroidism renders the BBM more fluid and that shortterm treatment with $\mathrm{T}_{3}$-replacement decreases the fluidity promptly, although not to control levels.

\section{DISCUSSION}

This study examined the effects of congenital hypothyroidism on maturation of $\mathrm{P}_{\mathrm{f}}$ in BBMV. In BBMV obtained from rabbits with chemically induced congenital hypothy- roidism, $\mathrm{P}_{\mathrm{f}}$ was higher than in BBMV from euthyroid animals. This effect was reversed by replacement of $T_{3}$ for $3 \mathrm{~d}$. $\mathrm{E}_{\mathrm{a}}$ and mercury inhibition of $\mathrm{P}_{\mathrm{f}}$ were not different among the three groups. Hypothyroidism was also associated with a higher AQP1 protein abundance and membrane fluidity, which were partially reversed by $\mathrm{T}_{3}$-replacement, indicating that the effects are mediated by thyroid hormone rather than by direct effects of PTU. The combined results

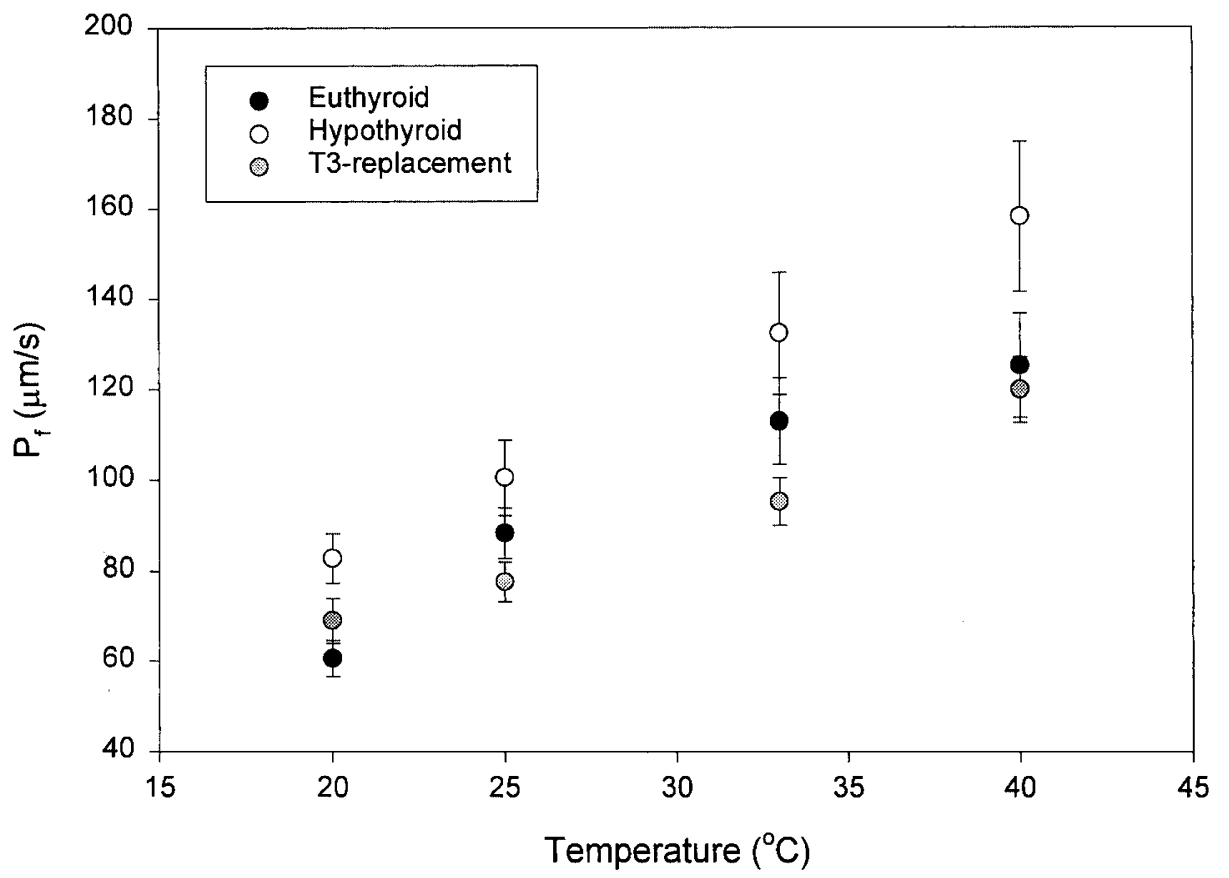

Figure 2. $\mathrm{P}_{\mathrm{f}}$ for euthyroid, hypothyroid and $\mathrm{T}_{3}$-replacement groups at $20-40^{\circ} \mathrm{C}$. Means were calculated using repeat measures ANOVA. Error bars denote $\mathrm{SEM}$. The $\mathrm{P}_{\mathrm{f}}$ of the hypothyroid BBMV was significantly higher than the euthyroid controls and the $\mathrm{T}_{3}$-replacement groups. 
show that thyroid hormone affects both channel-mediated water transport and transport through the lipid bilayer in BBMV simultaneously.

Maturation of water transport in the proximal tubule is a complex process. The neonatal tubule has an osmotic water permeability that is higher than that of the adult segment, yet the apical and basolateral membranes of the neonatal tubule have lower water permeabilities than the adult tubules $(14,2,3)$. The characteristics of the apical membrane water transport in the neonate include a lower $\mathrm{P}_{\mathrm{f}}$ and $\mathrm{AQP1}$ expression and a higher activation energy than the adult (2). The activation energy for water transport is thought to be determined by the membrane fluidity, which in turn is determined by the lipid and protein composition of the membrane (8).

Thyroid hormone concentrations in the newborn rabbit are significantly lower than the adult $(15,16)$. The level of thyroid hormone increases around the third week of life. We have previously shown that thyroid hormone affects both active and passive transport in the proximal tubule (7). We now demonstrate that thyroid hormone affects expression of AQP1. Because the adult expression of AQP1 is higher than the neonate, we expected to see a low expression level of AQP1 in the hypothyroid adult. However, we found the opposite. The hypothyroid animals had a higher expression of AQP1 and a higher osmotic water permeability. This was unexpected and is quite remarkable.

The effects of hypothyroidism on membrane fluidity were also remarkable. Previously, hypothyroidism was shown to not affect or even decrease fluidity of renal $\operatorname{BBMV}(17,18)$, but these data were obtained in adult rats, that had been euthyroid before and were treated with PTU for only 3 wk. On the other hand, in neonatal rats, $\mathrm{T}_{4}$ treatment decreased membrane fluidity of intestinal BBMV in perinatal $(<24 \mathrm{~h})$ and 12-d-old rats. This suggests that thyroid hormone accelerates the maturational decrease in membrane fluidity (19). The fluidity data from the present study are consistent with this, since $T_{3}$ replacement for $3 \mathrm{~d}$ decreased fluidity of BBMV. Thus, our results suggest that thyroid hormone is required for the normal development of the lipid bilayer of the renal brush border membrane.

The effects of hypothyroidism on the $\mathrm{P}_{\mathrm{f}}$ of the brush border membrane may also be the result of well organized adaptive mechanisms to effects hypothyroidism has on other proximal tubule functions or on functions of other segments of the nephron. In rabbits that are hypothyroid from birth, proximal straight tubule $\mathrm{NaCl}$ transport is reduced and is reversible by $\mathrm{T}_{3}$-replacement (7). With solute transport being limited in the hypothyroid animal, an increased $\mathrm{P}_{\mathrm{f}}$ would ensure that fluid reabsorption was not limited as is the case with the AQP1 knockout mice (20). Hypothyroidism is also associated with changes in tubule length and diameter, which may lead to decreases in the brush border membrane surface area and thus require higher $\mathrm{P}_{\mathrm{f}}$ to allow for sufficient reabsorption of water. The increased $\mathrm{P}_{\mathrm{f}}$ of the brush border membrane may also reflect a greater fluid reabsorption in the proximal tubule that serves as a compensatory mechanism for impaired function of the more distal nephron segments. The effects of hypothyroidism on water transport may also play a role in the development of myxedema.

In conclusion, this study shows that congenital hypothyroidism in rabbits is associated with an increased $\mathrm{P}_{\mathrm{f}}$ in renal BBMV

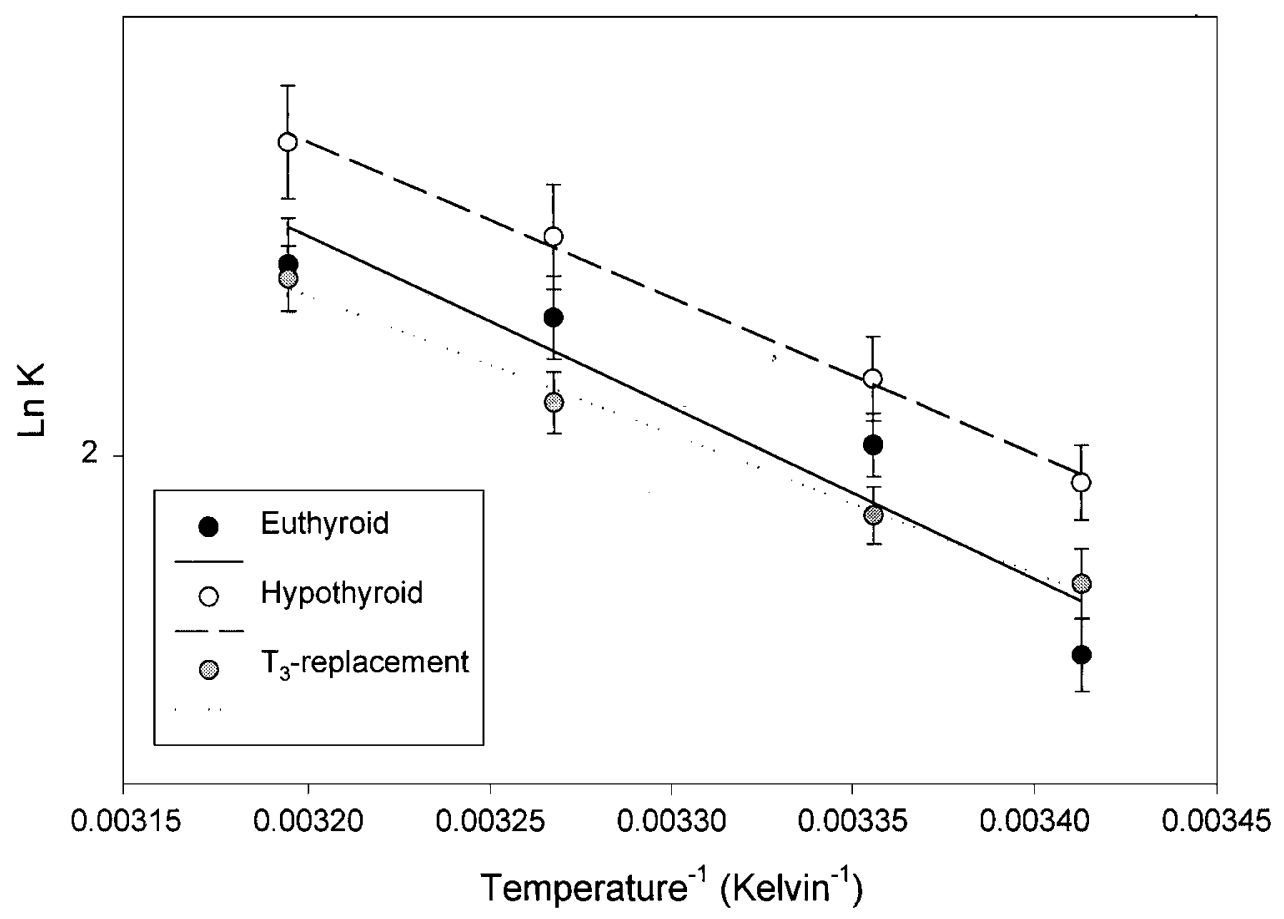

Figure 3. Arrhenuis plot of the temperature dependence of $P_{f}$. The activation energy $\left(E_{a}\right)$ was calculated from the slope of the regression lines. $E_{a}$ was not different among the three groups. Error bars denote SEM. The $\mathrm{P}_{\mathrm{f}}$ of the hypothyroid BBMV was significantly higher than the euthyroid controls and the $\mathrm{T}_{3}$-replacement groups. 


\section{AQP1}

B ACTIN
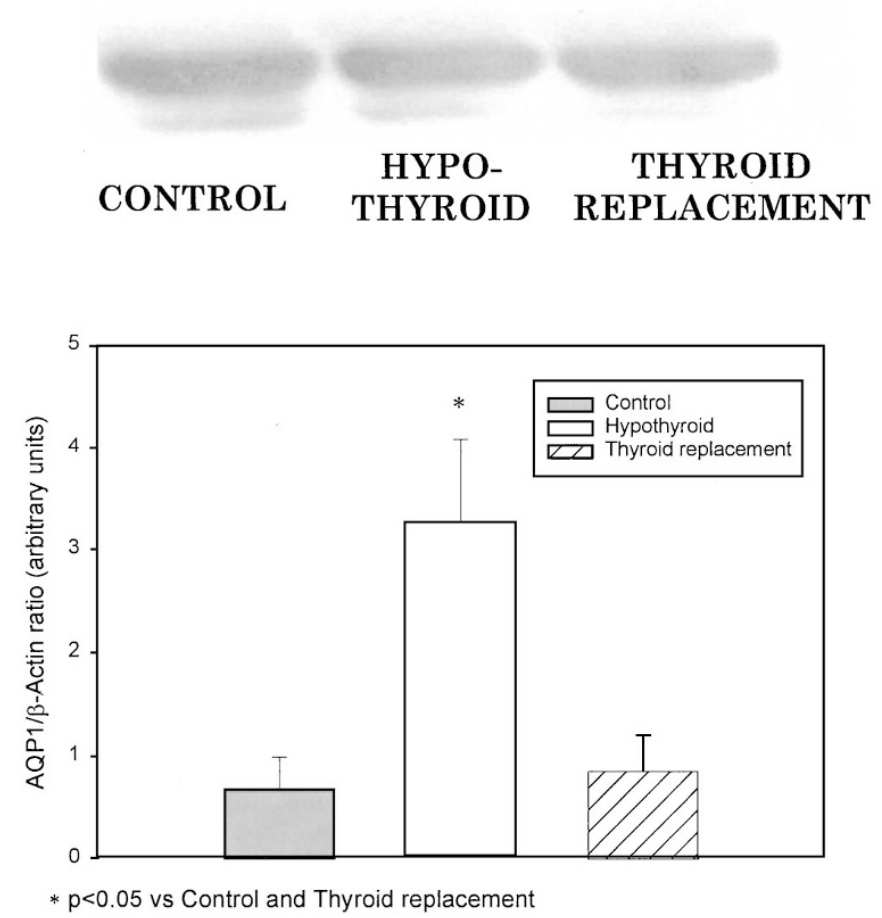

Figure 4. Immunoblot of $\mathrm{AQP} 1$ protein abundance. Lanes were loaded with $40 \mu \mathrm{g}$ protein. Densitometry showed $\mathrm{AQP} 1 / \beta$-actin ratio: hypothyroid $3.27 \pm 0.81$, control $0.66 \pm 0.33, \mathrm{~T}_{3}$-replacement $0.85 \pm 0.36 ; p<0.05$.

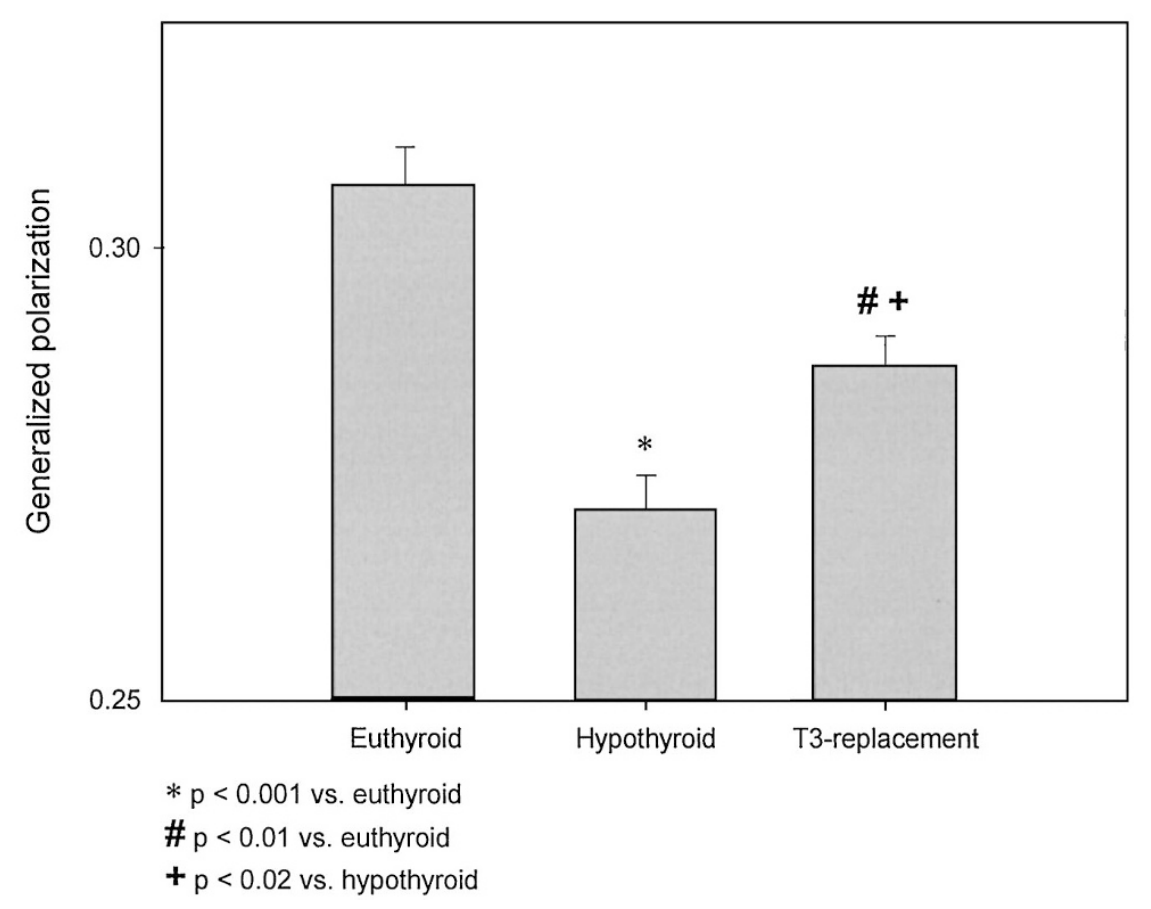

Figure 5. Generalized polarization (GP) of steady-state Laurdan fluorescence. BBMV (100 $\mu \mathrm{g}$ protein) were incubated with $0.33 \mathrm{nmol}$ Laurdan at $37^{\circ} \mathrm{C}$ for $20 \mathrm{~min}$ before measurements. Excitation wavelength was $340 \mathrm{~nm}$. GP was calculated from the emission intensities at 440 and $490 \mathrm{~nm}$. Membrane fluidity is inversely related to GP, indicating that hypothyroidism results in a lower fluidity of BBMV and that $\mathrm{T}_{3}$-replacement for three days decreases fluidity, but not to euthyroid levels. 
at 9 wk of age. This is due to a higher protein expression of AQP1 as well as a delay in the maturational decrease of membrane fluidity. These effects are readily reversible by $\mathrm{T}_{3}$-replacement. This suggests that thyroid hormone is not required for the maturational increase of $\mathrm{P}_{\mathrm{f}}$ in $\mathrm{BBMV}$, although thyroid hormone may play a role in the normal development of the membrane lipid composition. The mechanism by which thyroid affects $\mathrm{P}_{\mathrm{f}}$ and aquaporin 1 expression remains to be elucidated.

Acknowledgments. The authors thank Vangipuram Dwakaranath for his technical assistance and Drs. Moshe Levi and Hubert Zajicek (Veterans Administration Medical Center, Dallas, TX, U.S.A.) for advice and assistance with fluidity measurements.

\section{REFERENCES}

1. Schafer JA 1990 Transepithelial osmolality differences, hydraulic conductivities, and volume absorption in the proximal tubule. Annu Rev Physiol 52:709-726

2. Quigley R, Harkins EW, Thomas PJ, Baum M 1998 Maturational changes in rabbi renal brush border membrane vesicle osmotic water permeability. J Membr Biol 164:177-185

3. Quigley R, Gupta N, Lisec A, Baum M 2000 Maturational changes in rabbit renal basolateral membrane vesicle osmotic water permeability. J Membr Biol 174:53-58

4. Agre P, Preston GM, Smith BL, Jung JS, Raina S, Moon C, Guggino WB, Nielsen S 1993 Aquaporin CHIP: the archetypal molecular water channel. Am J Physiol 265:F463-F476

5. Baum M, Dwarakanath V, Alpern RJ, Moe OW 1998 Effects of thyroid hormone on the neonatal renal cortical $\mathrm{Na}+/ \mathrm{H}+$ antiporter. Kidney Int 53:1254-1258
6. Euzet S, Lelievre-Pegorier M, Merlet-Benichou C 1996 Effect of 3,5,3'triiodothyronine on maturation of rat renal phosphate transport: kinetic characteristics and phosphate transporter messenger ribonucleic acid and protein abundance. Endocrinology 137:3522-3530

7. Shah M, Quigley R, Baum M 2000 Maturation of proximal straight tubule $\mathrm{NaCl}$ transport: role of thyroid hormone. Am J Physiol Renal Physiol 278:F596-F602

8. Finkelstein A 1987 Water movement through lipid bilayers, pores, and plasma membranes: theory and reality. John Wiley and Sons, Inc., New York, pp 1-55

9. Quigley R, Flynn M, Baum M 1999 Maturational changes in rabbit renal brush border membrane vesicle urea permeability. Pediatr Res 45:143-147

10. van Heeswijk MPE, and van Os CH 1986 Osmotic water permeabilities of brush border and basolateral membrane vesicles from rat renal cortex and small intestine. J Membr Biol 92:183-193

11. Berry CA 1983 Water permeability and pathways in the proximal tubule. Am J Physiol 245:F279-F294

12. Berry CA 1985 Characteristics of water diffusion in the rabbit proximal convoluted tubule. Am J Physiol 249:F729-F738

13. Levi M, Shayman JA, Abe A, Gross SK, McCluer RH, Biber J, Murer H, Lotscher M, Cronin RE 1995 Dexamethasone modulates rat renal brush border membrane phosphate transporter mRNA and protein abundance and glycosphingolipid composition. $\mathrm{J}$ Clin Invest 96:207-216

14. Quigley R, and Baum M 1996 Developmental changes in rabbit juxtamedullary proximal convoluted tubule water permeability. Am J Physiol 271:F871-F876

15. Walker P, Dubois JD, Dussault JH 1980 Free thyroid hormone concentrations during postnatal development in the rat. Pediatr Res 14:247-249

16. Wysocki SJ, and Segal W 1972 Influence of thyroid hormones on enzyme activities of myelinating rat central-nervous tissues. Eur J Biochem 28:183-189

17. Prasad R, Kumar V, Kumar R, Singh KP 1999 Thyroid hormones modulate zinc transport activity of rat intestinal and renal brush-border membrane. Am J Physiol 276:E774-E782

18. Sagawa K, Murer H, Morris ME 1999 Effect of experimentally induced hypothyroidism on sulfate renal transport in rats. Am J Physiol 276:F164-F171

19. Schwarz SM, Hostetler B, Ling S, Mone M, Watkins JB 1985 Intestinal membrane lipid composition and fluidity during development in the rat. Am J Physiol 248:G200-G207

20. Schnermann J, Chou CL, Ma T, Traynor T, Knepper MA, Verkman AS 1998 Defective proximal tubular fluid reabsorption in transgenic aquaporin-1 null mice. Proc Natl Acad Sci U S A 95:9660-9664 